\title{
PLISSIT model: sexual counseling for breast cancer survivors
}

\author{
Modelo PILSET: aconsel hamento sexual para sobreviventes do câncer de mama \\ Modelo PILSET: asesoramiento sexual para sobrevivientes del cáncer de mama
}

\section{Natália Gondim de Almeida' ORCID: 0000-0002-7254-4360}

Débora Fernandes Britto" ORCID: 0000-0001-6248-8054

Juliana Vieira Figueiredo"'I ORCID: 0000-0002-6887-333X

Thereza Maria Magalhães Moreira' ORCID: 0000-0003-1424-0649

Rhanna Emanuela Fontenele Lima de Carvalho' ORCID: 0000-0002-3406-9685

Ana Virgínia de Melo Fialho' ORCID: 0000-0002-4471-1758

'Universidade Estadual do Ceará. Fortaleza, Ceará, Brazil. "Universidade Federal do Ceará. Fortaleza, Ceará, Brazil. I"Centro Universitário Estácio do Ceará. Fortaleza, Ceará, Brazil.

How to cite this article: Almeida NG, Britto DF, Figueiredo JV, Moreira TMM, Carvalho REFL, Fialho AVM. PLISSIT model: sexual counseling for breast cancer survivors. Rev Bras Enferm. 2019;72(4):1109-13. doi: http://dx.doi.org/10.1590/0034-7167-2018-0525

Corresponding Author:

Natália Gondim de Almeida E-mail: natygondim@gmail.com

Submission: 07-13-2018 Approval: 10-03-2018

\begin{abstract}
Objective: Reporting the experience of use of the PLISSIT model as tool for the nursing care of breast cancer survivors with sexual dysfunction. Method: case study developed from January to August 2017, in the outpatient mastology clinic and sexuality service of a maternity in Fortaleza, Ceará, Brazil, with 15 breast cancer survivors. Results: sexual counseling sessions were conducted using the PLISSIT model to address sexual issues, highlighting the particularities of women who experience survival after the treatment of breast cancer. Final considerations: the model used in the practice of nursing care is customary and allows identifying issues experienced by women, as it has easy availability and practicality for use by nursing professionals, helping to address sexual matters with greater tranquility.

Descriptors: Breast Neoplasms; Sexuality; Sexual Counseling; Nursing; Women's Health.
\end{abstract}

\section{RESUMO}

Objetivo: Relatar a experiência do uso do modelo PILSET como ferramenta de cuidado de enfermagem para sobreviventes de câncer de mama com disfunção sexual. Método: relato de experiência desenvolvido de janeiro a agosto de 2017, realizado no ambulatório de mastologia em conjunto com o serviço de sexualidade de uma maternidade-escola de Fortaleza, Ceará, Brasil, com 15 sobreviventes de câncer de mama. Resultados: realizaram-se sessões de aconselhamento sexual, utilizando o modelo PILSET para trabalhar questões sexuais, destacando as particularidades da mulher que vivencia a sobrevida após o tratamento de câncer de mama. Considerações finais: o modelo utilizado na prática de cuidado de enfermagem é usual e permite identificar questões vivenciadas pela mulher, pois é uma ferramenta de fácil disponibilidade e praticidade para profissionais de enfermagem, auxiliando abordar questões sexuais com maior tranquilidade.

Descritores: Neoplasias da Mama; Sexualidade; Aconselhamento Sexual; Enfermagem; Saúde da Mulher.

\section{RESUMEN}

Objetivo: Informar la experiencia del uso del modelo PILSET como herramienta de cuidado de enfermería para sobrevivientes de cáncer de mama con disfunción sexual. Método: relato de experiencia desarrollado de enero a agosto de 2017, realizado en el ambulatorio de mastología junto con el servicio de sexualidad de una maternidad-escuela de Fortaleza, Ceará, Brasil, con 15 sobrevivientes de cáncer de mama. Resultados: se realizaron sesiones de asesoramiento sexual, utilizando el modelo PILSET para trabajar cuestiones sexuales, destacando las particularidades de la mujer que vive la sobrevida tras el tratamiento del cáncer de mama. Consideraciones finales: el modelo utilizado en la práctica del cuidado de enfermería es usual y permite identificar cuestiones vivenciadas por la mujer, pues es una herramienta de fácil disponibilidad y practicidad para profesionales de enfermería, ayudando a abordar cuestiones sexuales con mayor tranquilidad.

Descriptores: Neoplasias de la Mama; Sexualidad; Consejo Sexual; Enfermería; Salud de la Mujer. 


\section{INTRODUCTION}

The diagnosis of breast cancer and its treatment, including surgery, chemotherapy, radiation and hormonal therapy, can cause changes in sexuality in the long run. The effects can be physical and emotional, contributing to the emergence of problems of sexual nature, which are not addressed frequently by nurses, usually due to communication barriers between professional and patient. Thus, the incorporation of appropriate questions in the evaluation by nurses gives the patient the opportunity to address sexual health issues ${ }^{(1)}$, favoring communication.

The PLISSIT model, proposed by Jack S. Annon ${ }^{(2)}$, is an effective communication model that theoretically supports interventional approaches, having been developed to be used by professionals in consultations for the care of sexuality and sexual health. This model allows discussing sexuality, offering specific suggestions such as change of positions, use of lubricants, among other recommendations according to the needs of individual patients in therapy, promoting, in more complex cases, the referral to intensive therapy with specialized professionals ${ }^{(2)}$. This is one of the approaches in the discussion on sexual health, and should be used by health professionals with communication skills associated with psycho-sexual problems ${ }^{(3)}$.

There is evidence that there is a knowledge gap in the provision of care with regard to sexuality, therefore, the deconstruction of the barriers surrounding the sexual theme becomes relevant ${ }^{(4)}$. Oftentimes, talking about sex and sexuality seems difficult, which leads nurses not to address these topics. Some of the barriers identified include limited time for the nursing professional during the consultation and a knowledge gap in relation to the preparation of resources, as well as appropriate access to the source of the problem ${ }^{(5)}$.

The PLISSIT model has a positive effect on the rehabilitation of breast cancer survivors, i.e., there is evidence of improvement of quality of sexual life and sexual function after mastectomy surgery. Nurses can use the model in health environments to address the couples' sexual needs, weaknesses and difficulties. The intervention can be performed alongside the chemo and radiotherapy to collaborate with the improvement of the couple's and individuals' quality of life and sexual function. Thus, it has a positive effect on the resolution of sexual issues in women subjected to mastectomy surgery, in addition to improving the sexual function ${ }^{(6)}$.

This study was justified by the need to socialize experiences in the production of knowledge and in nursing and health practices. In this sense, the presentation of nursing interventions to the scientific community stands out, becoming essential especially within the clinical context, because it is part of the work of researchers.

Given the above, it is extremely important to give emphasis to the clinical trials performed with the PLISSIT model to disseminate and encourage the use of interventions in the practice of care of breast cancer survivors (BCS) with sexual dysfunction.

\section{Theoretical foundations of the PLISSIT model's characteristics}

The acronym PLISSIT stands for the four intervention levels - Permission, Limited Information, Specific Suggestions, and Intensive Care. It was designed for sexual problems, including nursing care actions within the sexual dimension.
It was developed by psychologist Annon, in 1976, for use during consultations, and can be adopted by any health professional in the care of patients with complaints related to sexuality and sexual health ${ }^{(2)}$.

The PLISSIT model promotes four intervention levels, and each of them designates a suggested method to deal with sexual problems. As can be seen in the model's graphic representation (Figure 1), the horizontal lines would be sexual problems or concerns over time. A determined number of issues can be accessed in each level of the theoretical model ${ }^{(2)}$.

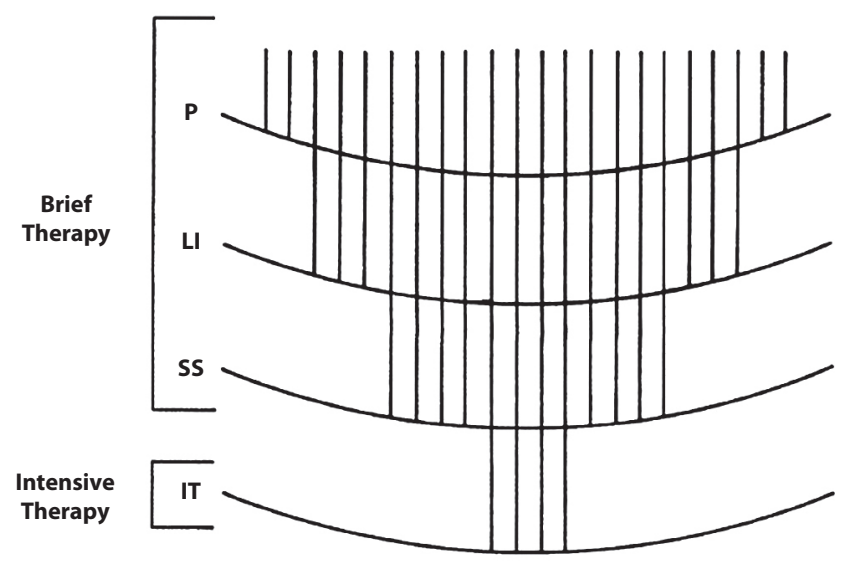

Source: Annon ${ }^{(2)}$

Figure 1 - Graphical representation of the PLISSIT Model

Thus, the first three intervention levels - Permission, Limited Information and Specific Suggestions - are considered a brief therapy, which can deal with most of the patients' problems; those which are not accessible should be referred to the intensive therapy stage. The model has a distinct number of advantages and can be used in a variety of cases and adapted to the individual needs of each patient ${ }^{(3)}$.

The first level of treatment - Permission - gives the patients freedom to talk about things that might be bothering them and, thus, helps them deal with the situation and understand this as a problem they do not need to worry or feel guilty about, so they may resume their previous conducts. The second level - Limited Information - promotes information about a fact that is specifically targeted and relevant to particular issues, which could result in them conducting their previous conducts or doing something different. If the limited information are not sufficient to solve the sexual issues, the professionals have two options available: referral to intensive care treatment or, if they have a proper context, knowledge, skills and experience, they may proceed to the third level of treatment ${ }^{(2)}$.

The Specific Suggestion level must, before giving out specific suggestions, obtain information from what will be useful to the patient, according to the individual circumstances. The fourth level of treatment is indicated only for patients who could not be treated in the first three steps, with them being referred to a specialist for deepening their sexual issues ${ }^{(2)}$.

As it is a model that aims to treat sexual problems, it is possible, during its use in research, to measure the intervention's effect in remedying or improving the population's sexual problems ${ }^{(2,6-10)}$.

In this work, the process of using the PLISSIT Model for sexual counseling of breast cancer survivors (BCS) is presented. 


\section{OBJECTIVE}

Reporting the experience of use of the PLISSIT model as tool for the nursing care of BCS with sexual dysfunction.

\section{METHOD}

\section{Ethical aspects}

The ethical aspects were considered seeing as the survey was developed following the approval of the Committee of Ethics in Research with Human Beings of the Assis Chateaubriand Maternity.

\section{Study design}

This is the case study of the application of a sexual counseling intervention based on the PLISSIT model, for breast cancer survivors.

The five sessions of the intervention occurred in the outpatient mastology clinic in conjunction with the sexuality service of the aforementioned maternity in Fortaleza, Ceará, Brazil, in the period from January to August 2017.

To publicize the sessions, pamphlets were distributed in the ambulatory and in the associations of support to women undergoing mastectomy surgery, with information about their date, location and contact number. The contact information of women interested in participating were registered, so they could be informed, via phone call, about the schedule of the meetings and the attendance site. Thus, the BCS themselves chose to participate, those who were chosen having had undergone mastectomy surgery at least six months prior, having been over 18 years old and having had already initiated their sexual activity. Fifteen breast cancer survivors participated in total.

The intervention was based on the PLISSIT Model as a nursing care tool, focusing on the management of sexual dysfunction, with the aim of improving the quality of the women's survival in the dimension of sexuality and the resulting quality of life. The frequency of the intervention's sessions was once a week, for five weeks, with approximately 120 minutes duration. The Female Sexual Function Index (FSFI) was applied before the first and after the last session, five weeks after the first collection for analysis of the impact of the Model as intervention.

The content of the experience derives from the intervention protocol designed for application in the sexual psychotherapy sessions, to discuss situations that involve sexuality and sexual dysfunctions, as proposed by the PLISSIT model. To build the intervention protocol, a Nurse and a Sexologist devised actions to be applied during the sessions.

The model in question was chosen for being easy to incorporate in the daily practice of nursing professionals ${ }^{(6)}$. Thus, the P, IL, SE and IT steps were written together as a way to create a proper setting for

\section{P}

Using scenes from a film where the protagonist had undergone mastectomy surgery in conjunction with guiding questions about life changes after breast cancer.
IL

Guidance on the female anatomy and masturbatory practices, using pelvis and vagina models. the BCS, such as: the choice of a film's scene, addressing conditions similar to those of this population, characterization of permission questions for discussing the subject, use of pelvic floor models for limited information, language and behaviors, as well as use of lubricants, high heels, vibrator, lingerie and erotic material (whip, handcuffs etc.) for the specific suggestion.

\section{RESULTS}

\section{Application of sexual counseling intervention for breast cancer survivors - SCIBCS}

The activity was directed by a protocol that served to guide the implementation of the sexual counseling intervention for breast cancer survivors (SCIBCS). The group sessions followed the pre-established instructions described in the protocol, which were adapted to the population receiving counseling.

The interventions are deeply effective in various contexts, however, it is sometimes possible to note differences in effectiveness, which should be adapted to a given context, respecting the patients in relation to their cultural and social issues ${ }^{(7)}$.

There were guidelines for the moderator of the group sessions, informing them of the maximum duration of each session, which was 2 hours; of the intervention's target population - breast cancer survivors; and of the necessary resources, which were organized prior to the meetings (Figure 2).

In the first session, we used Permission - first level of the PLISSIT model. It was initiated with a dynamic presentation adopting the role reversal technique, in which each participant told their characteristics to the person on their side, who would then present them to the group. After the presentations, scenes of a film that depicted the protagonist, a woman who had undergone mastectomy surgery, in moments of intimate relationship, were shown.

Subsequently, questions about their sexual life, body and sexuality, type of relationship with their partner, situations of discomfort in their sexual life, what could be done to modify this discomfort, mood swings after the mastectomy surgery and if any changes in the relationship were observed after it were asked. To end the session, the professionals - nurse and sexologist-, responsible for applying the intervention emphasized the importance of returning for the subsequent meetings.

The second session, in which Limited Information was used, started with a reception and welcoming the participants back, reinforcing once again the need for participation in all meetings. After the reception, the one responsible for the intervention used pelvis and vagina models to clarify information about the female body, incorporating masturbatory practices and pleasure perception issues in the discussion. At the end, papers and pens were distributed for the participants to take home and write down questions with, to

Figure 2 - Illustration diagram of the SCIBCS based on the PLISSIT model, Fortaleza, Ceará, Brazil, 2018 
preserve the identity of each of them about the issues that could arise.

In the third session, Specific Suggestions, a box was presented for the women to deposit their doubts in, which were then read and promptly answered, without display of authorship, being addressed in a more profound and specific manner. In addition to the clarification of questions and suggestion of using lube and sex toys with their partner, a self-image perception activity was carried out, in which the participants drew themselves, triggering the discussion about the perception of their self-image.

In the fourth session, the three levels of the model were used together - Permission, Limited Information and Specific Suggestions. The erotic workout technique was addressed, in which the women created a story making use of objects that were distributed among them, such as heels, vibrator, lube, lingerie and erotic material (whip, handcuffs, among others).

At the fifth session, a recap of all previous sessions was conducted and, through discussion, the professionals who mediated the meetings referred the cases that needed individual accompaniment to the sexologist, so intensive therapy could be carried out. There was a $36.79 \%$ increase of the FSFI scores using the PLISSIT Model, with variation between 13.78 and 18.85 after five weeks.

\section{DISCUSSION}

\section{Benefits and challenges of using the PLISSIT model in nursing care practice}

Interventions are deeply effective in various contexts. However, it is important to select the most suitable. Professionals working in the field of sexuality need to be sensitive to apply therapies in an individualized manner. Ever since therapeutic interventions were introduced in sexuality-related practices, the designing and structuring of protocols to treat and manage the sexual problems of women has been of great value ${ }^{(7)}$.

In this sense, becoming acquainted with the population through reviews of the literature and insertions in the field of study become extremely necessary measures when working with aspects of sexuality, in addition to emphasizing that some changes ensue after the treatment and that it is normal for the breast cancer survivor to adopt different behaviors in relation to her sexuality. Sharing experiences helps turning what would previously have been deemed as "abnormal" into something within the standards considered as normal by the patients, as they become aware that these are common situations among women who have experienced breast cancer.

Sexual dysfunction in people with cancer is a significant problem. Thus, the use of guidelines that address issues within the sphere of sexuality improves the sexual function of these individuals. This includes issues such as body image, sexual response, intimacy and relationship, altered sexual function, sexual satisfaction and vasomotor and genital symptoms in women. Sexual dysfunction interventions are organized in pharmacological approaches, psychosocial counseling and sexual response mechanisms. Counseling has an important therapeutic role, and the risks related to its use are low ${ }^{(8)}$.

The discussion on health and sexual dysfunction is recommended, and must be initiated by a member of the health team in the care of cancer survivors. Sexual counseling should be offered to all patients with cancer, to promote the quality of the care involved in the improvement of sexual response, body image, intimacy and relationship issues and sexual satisfaction ${ }^{(9)}$.

Nurses can help improve the sexual function in women using the PLISSIT model. There are studies ${ }^{(6,10)}$ showing that the use of sexual counseling strategies alleviates pain, among other factors, being considered a model with great effectiveness, which makes it a very useful intervention method in practice, mainly due to its availability and accessibility for use by health professionals.

In this context, the idea that there is a need among health professionals, including nurses, to address sexual issues in breast cancer survivors is emphasized.

\section{Study limitations}

Among the limitations, it may be emphasized that conducting the groups' meetings in a location which the women needed to commute to somewhat hindered their adherence to the counseling sessions, which limited the number of participants willing to attend them.

\section{Contributions to the field of nursing}

The PLISSIT model allows nurses to handle and treat sexual dysfunctions, promoting a care that is tailored according to the particularities of the population being assisted, ensuring its quality in the rehabilitation of sexual problems that may be treated within the steps provided by the model and contributing to the quality of life of breast cancer survivors. As it is a model used by nurses, it becomes a strategy that can be incorporated into the practice of evidence-based care, since its effectiveness has been proven in other studies.

\section{FINAL CONSIDERATIONS}

The application of the PLISSIT model as nursing care practice allows identifying the method as customary, offering a simple way of handling and addressing issues nurses find difficulties dealing with. The model, while healthcare tool, can be adapted to any population; however, it is important to know the individual characteristics of the population in question before using it, so non-relevant information is not provided.

The experience of using the PLISSIT model was enriching for both researchers and participants of the intervention. The activity was conducted by two professionals with different backgrounds - a nurse and a physician specialized in sexology -, which reinforces the idea of access to sexual issues being treated by a multidisciplinary team. However, it should be noted that nurses have the competence, skill and curriculum necessary to intervene in sexual matters, provided they are trained for this, and may do so in individual or collective care during the nursing consultation.

Therefore, it is suggested that nurses may incorporate into their care practice approaches to sexual matters, because the model is customary and may be a way to treat simpler sexual issues. 


\section{REFERENCES}

1. Boswell EN, Dizon DS. Breast cancer and sexual fuction. Transl Androl Urol. 2015;4(2):160-8. doi: 10.3978/j.issn.2223-4683.2014.12.04

2. Annon JS. The PLISSIT Model: a proposed conceptual scheme for the behavioral treatment of sexual problems. J Sex Educ Ther. 1976;2(1):115. doi: 10.1080/01614576.1976.11074483

3. Dizon DS, Suzin D, Mcllvenna S. Sexual health as a survivorship issue for female cancer survivors. Oncologist. 2014;19(2):202-10. doi: 10.1634/theoncologist.2013-0302

4. Costa LHR, Coelho EAC. Sexualidade e a interseção com o cuidado na prática profissional de enfermeiras. Rev Bras Enferm. 2013;66(4):493500. doi: 10.1590/S0034-71672013000400005

5. Bober SL, Reese JB, Barbera L, Bradfor A, Carpenter KM, Goldfarb S, et al. How to ask and what to do: a guide for clinical inquiry and intervention regarding female sexual health after cancer. Curr Opin Support Palliat Care. 2016;10(1):44-54. doi: 10.1097/ SPC.0000000000000186

6. Faghani S, Ghaffari F. Effects of sexual rehabilitation using the PLISSIT Model on quality of sexual life and sexual functioning in postmastectomy breast cancer survivors. Asian Pac J Cancer Prev. 2016;17(11):4845-51. doi: 10.22034/APJCP.2016.17.11.4845

7. Salmani Z, Zargham-Boroujeni A, Salehi M, Killen TK, Merghati-Khoei E. The existing therapeutic interventions for orgasmic disorders: recommendations for culturally competent services, narrative review. Iran J Reprod Med. 2015;13(7):403-12.

8. Barbera L, Zwall C, Elterman D, McPherson K, Wolfman W, Karz A, et al. The interventions to address sexual problems in people with cancer. Curr Oncol. 2017;24(3):192-200. doi: 10.3747/co.24.3583

9. Carter J, Lacchetti C, Andersen BL, Barton DL, Bolte S, Damast S, et al. Interventions to address sexual problems in people with cancer: American Society of Clinical Oncology Clinical Practice Guideline Adaptation of Cancer Care Ontario Guideline. J Clin Oncol. 2018;36(5):492511. doi: 10.1200/JCO.2017.75.8995

10. Emam AMM, Elmenim SOA, Sabry SS. Effectiveness of application of PLISSIT counseling modelo on sexuality among women with dyspaurenia. Am J Nurs Sci. 2018;7(2):73-83. doi: 10.11648.j.ajns.20180702.15 